\title{
Formación docente en profesores de la Licenciatura en Administración en FACPYA, UANL
}

Teacher training in teachers of the Bachelor's Degrees in Management in

FACPYA, UANL

Formação de professores professores da Licenciatura em Administração em

FACPYA, UANL

Juan Manuel Chávez Escobedo

Universidad Autónoma de Nuevo León, México

chavezmaster10@gmail.com

\section{Resumen}

Los futuros licenciados en administración deben estar bien capacitados en distintas áreas del conocimiento, como finanzas, economía, derecho y matemáticas. La distribución congruente de cargas académicas garantiza que el proceso académico brinde al licenciado en administración una formación eficaz.

Palabras clave: formación docente, pedagogía, cátedra en licenciatura.

\section{Abstract}

Future graduates in management must be well trained in different fields of knowledge, such as finance, economics, law, and mathematics. The consistent academic load distribution ensures the academic process to provide effective training to the Bachelor in Management. Key Words: teacher education, pedagogy, Bachelor Chair. 


\section{Resumo}

Futuros licenciados em administração deve ser bem treinados em diferentes áreas do conhecimento, tais como finanças, economia, direito e matemática. A distribuição consistente de cargas acadêmicos garante que o processo acadêmico fornece o grau de formação administração eficaz.

Palavras-chave: formação de professores, Pedagogia, Professor grau.

Fecha recepción: Enero $2016 \quad$ Fecha aceptación: Junio 2016

\section{Introducción}

La formación docente en México es responsable de las Escuelas Normales de Educación, instituciones donde se forman los profesores que desean contribuir al desarrollo de la nación y cuyo modelo contempla formación disciplinar, pedagógica e integral, aplicándose esta última durante la vida cotidiana en forma de valores, ética y civilidad.

En Francia se encuentra la Escuela Normal Superior de París, fundada en 1794, donde se forman profesores, investigadores y líderes, como políticos, líderes de estado o empresariales, entre otros.

Generalmente, en México se recurre a normalistas para impartir clases desde la educación inicial hasta la secundaria, mientras que en el nivel bachillerato se contratan tanto normalistas como universitarios. En la actualidad, los niveles de bachillerato y nivel superior buscan los servicios docentes de universitarios.

Los docentes de nivel superior enseñan de acuerdo a su preparación, por ejemplo, un médico imparte cátedra sobre anatomía o un licenciado en administración imparte cátedra sobre administración estratégica. Por ese motivo, las universidades deben generar sus procesos de inducción y capacitación académica, pues les permite preparar a sus 
catedráticos para que puedan desempeñarse mejor $\mathrm{y}$, por lo tanto, formar futuros profesionistas de más calidad.

\section{Antecedentes}

La Universidad Autónoma de Nuevo León (UANL), desde que fue fundada en 1933 hasta la actualidad, ha contribuido al crecimiento y desarrollo constante del sector productivo y social del país, formando profesionistas en distintas áreas del conocimiento, tales como: contaduría, medicina, derecho, filosofía, desarrollo humano, matemáticas, biología, arquitectura, psicología, economía, administración, odontología, agronomía, política, ingeniería, comunicación, química, geología, arquitectura, veterinaria y técnicos especializados, todos ellos engranes operativos y funcionales de la industria, comercio, gobierno, banca de Nuevo León y el resto de la zona norte del país. La UANL ha preparado profesionistas que han alcanzado el éxito incluso en otros países.

La Facultad de Contaduría Pública y Administración es una IES (Institución de Educación Superior) fundada por un grupo de destacados contadores públicos. En ese entonces era presidente Adolfo Ruíz Cortines, el gobernador del estado era el doctor Ignacio Morones Prieto y el rector de la universidad el licenciado Raúl Rangel Frías. Su primer director fue el CP Ramón Cárdenas Coronado $(\dagger)$.

Dentro de su oferta educativa de nivel licenciatura se encuentra:

- Administración

- Contaduría Publica

- Informática Administrativa

- Negocios Internacionales

Y en nivel posgrado:

- Maestría en Administración de Empresas

- Maestría en Contaduría

- Maestría en Administración Internacional 
- Maestría en Negocios Internacionales

- Doctorado en Filosofía con Especialidad en Administración

- Doctorado en Contaduría

La facultad dentro de sus procesos de mejora contempla la educación continua de sus profesores. El presente trabajo de investigación analiza la formación del profesorado, en especial de los que participan en el programa educativo de licenciatura en administración, puesto que es el programa que demanda profesores en ciencias económico-administrativas, por ejemplo, administradores, economistas, contadores y financieros.

\section{Método}

Para ello se llevó a cabo un trabajo cualitativo con ayuda del estudio del caso, la revisión de literatura y la aplicación de una encuesta a dos grupos del noveno semestre de la licenciatura en administración. La muestra fue a conveniencia inicial, de donde se tomó la opinión de los estudiantes sobre las características deseables en sus profesores partiendo de su experiencia, observación y análisis reflexivo, ya que cursan el último semestre de la carrera.

\section{Desarrollo}

La formación docente debe responder a un plan de diseño adecuado para el desarrollo de la profesión del magisterio. Con respecto a la educación superior, los maestros deben impartir sus clases basándose en un perfil que debe incluir habilidades interpersonales y de comunicación. Aquí los campos formativos más importantes son dos:

- Formación pedagógica

Que tiene que ver con la preparación en las formas de enseñar, las teorías de aprendizaje, la didáctica y estrategias de enseñanza, la comunicación en la enseñanza, desarrollo de tecnologías de enseñanza y aprendizaje, etcétera. 
- Formación disciplinar

Relacionada con los contenidos específicos de la carrera o disciplina en particular. En el caso de los (LA) licenciados en administración, se refiere por ejemplo a recursos humanos, mercadotecnia, finanzas, administración, operaciones, etcétera.

Los profesores que imparten cursos en la FACPyA ingresan después de aprobar un examen de oposición a cátedra según lo marca el reglamento interno y la Ley Orgánica de la Universidad.

Para ello también deben contar con:

- Título de licenciatura y cédula profesional

- Título de maestría y la cédula correspondiente

- Experiencia profesional

- Gusto por la docencia

- Honorabilidad

Además, están aquellos requisitos que cada convocatoria en especial menciona, es decir, la profesión y el área de la carrera en la que se concursa.

Con respecto a la indagación preliminar se ha encontrado que la facultad emite convocatorias de concurso de oposición según las necesidades en recursos humanos generadas por defunciones, jubilaciones, promociones, etcétera. Éstas se toman en cuenta ya que modifican la estructura docente y pueden provocar la necesidad de contratar capital humano.

Para ello se sigue un proceso donde un jurado conformado por tres sinodales expertos en el área determina, mediante evaluaciones, si los candidatos a profesores son idóneos o no para la institución.

Si el candidato aprueba el examen se le invita a laborar como profesor de la facultad según las necesidades. De ser así, el nuevo profesor deberá pasar por un proceso de inducción 
docente y cursos formativos disciplinares y pedagógicos que coadyuven a su formación profesional.

En cuanto a la permanencia de la práctica docente en la facultad por más de once años, se observa que los docentes requieren capacitación continua debido en gran parte a la dinámica informativa en la que estamos inmersos y al grado de competitividad de nuestra sociedad y, por lo tanto, de los estudiantes (ellos pueden consultar bases de datos internacionales sobre las recientes investigaciones más relevantes). Asimismo, los docentes deben estar capacitados en esta área pero a un nivel más profundo porque son los facilitadores de procesos áulicos encaminados a forjar mejores profesionistas y personas.

La constante capacitación de los maestros propicia el uso de herramientas docentes tales como estrategias de enseñanza-aprendizaje, tecnología educativa, etcétera.

La sociedad actual requiere de personal capacitado, informado y dispuesto a seguir estudiando y aprendiendo para ser mejor y propiciar cambios que impulsen el desarrollo armónico en la población.

\section{Encuesta}

1. ¿Considera que sus maestros estan bien capacitados en pedagogía? Sí No

2. ¿Considera que sus maestros están bien capacitados en el área disciplinar? Sí No

3. ¿En qué área considera deben mejorar sus maestros?

Preparación disciplinar Desarrollo pedagógico

4. ¿Sus maestros utilizan tecnología educativa en sus clases?

Sí No 


\section{Resultados}

Total de la muestra: 120 estudiantes del noveno semestre de la licenciatura en administración de la Facultad de Contaduría Pública y Administración, Universidad Autónoma de Nuevo León, distribuidos en dos grupos de 60 estudiantes cada uno.

A continuación se muestran los resultados:

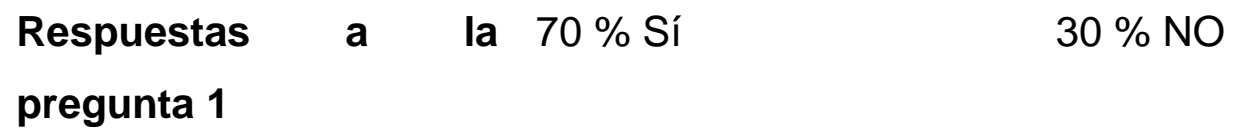

La totalidad de los encuestados mencionó que sus maestros utilizan tecnología educativa, algo muy importante ya que en nuestros días se debe estar actualizado.

Asimismo se observa que para la mayoría de los encuestados sus maestros son buenos y están bien capacitados tanto en el área pedagógica como en la disciplinar, aunque piensan que deberían capacitarse más en la última.

\section{Conclusiones}

Se recomienda revisar los procesos de inducción académica mediante el análisis del perfil de quien imparte los cursos, es decir, analizar la congruencia entre instructor-cursoformación académica-experiencia. También se debe motivar a los maestros que cumplen años de servicio a través de incentivos. Actualmente se otorgan reconocimientos por diez años de servicio, aunque no existe un estímulo económico fijo. Tal vez se puede dar por cada año de servicio un estímulo económico de mil pesos, es decir, otorgar diez mil pesos a quien cumpla diez años de servicio además de su reconocimiento, y al de quince años darle 
quince mil pesos y así sucesivamente, lo que motivaría a los docentes a permanecer en la institución.

Por otro lado, se recomienda hacer un análisis de congruencia entre las materias que el docente imparte y su perfil académico y profesional.

La educación continua es una tarea que no tiene fin, por lo que se debe seguir llevando a cabo en la facultad. La labor docente siempre debe desarrollar el conocimiento y las destrezas necesarias para su buen ejercicio.

\section{Bibliografía}

Abreu, J. y Badi, M. (2005). Investigación y enseñanza en responsabilidad social empresarial. En Formación de investigadores 1-10. México: Universidad Autónoma de Nuevo León.

Báez y Pérez, de Toledo Juan (2012). Investigación Cualitativa. México: Alfa Omega.

Cervantes, E. (2006). La sociedad del conocimiento. México: UNESCO.

La Universidad (s.f.). Recuperado el 11 de julio de 2016, de http://www.uanl.mx/universidad

Oferta educativa (s.f.). Recuperado el 11 de julio de 2016, de http://facpya.uanl.mx/ofertaeducativa/

Vela, J. (2000). Educación Superior: inversión para el futuro. En: Agüera E. y Zebadúa (Coords) (2001). La disputa por la educación. Editorial Aguilar. México. 